\title{
Garrafas de PET para Óleo Comestível - Avaliação da Barreira à Luz
}

\author{
Leda Coltro, Ana Elisa P. Buratin \\ Centro de Tecnologia de Embalagem, ITAL, SP
}

\begin{abstract}
Resumo: Os óleos comestíveis são produtos alimentícios sensíveis à luz, pois estão sujeitos à degradação por foto-oxidação, cujas conseqüências são escurecimento do produto e alteração de aroma e sabor, levando à rejeição do produto. Assim, quando os óleos são acondicionados em embalagens transparentes, a foto-oxidação torna-se a principal causa da deterioração oxidativa devido ao efeito da luz, encurtando a vida-de-prateleira do produto e daí surgindo a necessidade da utilização de absorvedores de UV, substâncias incolores que, quando incorporadas ao material da embalagem, absorvem a energia UV incidente ou inativam cromóforos excitados protegendo o produto. Este estudo foi desenvolvido com o objetivo de avaliar a barreira à luz de embalagens de PET disponíveis no mercado brasileiro utilizadas para o acondicionamento de óleo comestível por meio da obtenção de espectros de transmissão de luz especular no UV-Visível. As embalagens que apresentaram barreira à luz foram submetidas a ensaios analíticos com a finalidade de identificação e quantificação do aditivo utilizado. Os aditivos absorvedores de UV identificados nas embalagens plásticas foram relacionados quanto à restrição de uso e limites de composição estabelecidos pela Resolução 105 da Agência Nacional de Vigilância Sanitária ANVISA. Com isso foi possível fazer um diagnóstico do uso de absorvedores de UV em embalagens de PET utilizadas para o acondicionamento de óleo comestível disponíveis no mercado brasileiro.
\end{abstract}

Palavras-chave: PET, embalagens plásticas, óleo comestível, absorvedor de UV.

\section{PET Bottles for Edible Oil Packaging - Evaluation of the Light Barrier}

Abstract: The edible oils are light sensitive food products since they degrade by photo-oxidation, which promotes darkening of the product, alteration of its flavor and consequently its rejection. For edible oils packed in transparent packages, photo-oxidation becomes the main cause of the oxidative deterioration due to the light effect, reducing the shelf-life of the product. Then, it is necessary to use UV absorbers, colorless substances added to the package material, that absorb the incident UV radiation or deactivate the excited chromophores. The aim of this study was to evaluate the light barrier of PET bottles available in the Brazilian market used for edible oil packaging, by measuring the specular light transmission spectra obtained in the UV-Visible regions. The packages that showed light barrier were analyzed by HPLC in order to identify and quantify the additive. The UV absorbers identified in the plastic packages were considered with regard to the restriction and composition limits established by the Resolução 105 from Agência Nacional de Vigilância Sanitária ANVISA. It was then possible to make a diagnosis about the use of UV absorbers in PET bottles for edible oil packaging available in the Brazilian market.

Keywords: PET, plastic packaging, bottles, edible oil, UV absorber.

\section{Introdução}

O mercado de óleos comestíveis no Brasil movimentou cerca de US\$2,4 bilhões em 2002, correspondendo a 2,3 bilhões de litros. Deste total, $60 \%$ foram acondicionados em latas de folha-de-Flandres de $900 \mathrm{~mL}$ e $33 \%$ em garrafas de politereftalato de etileno - PET de $900 \mathrm{~mL}$ ( $864 \mathrm{mi}-$ lhões de garrafas). As garrafas de PET de $900 \mathrm{~mL}$ representavam apenas $11 \%$ do mercado em $1998^{[1]}$. O óleo de soja é o mais importante dos óleos vegetais produzidos no mundo devido sua qualidade e baixo custo.

Os óleos vegetais são ricos em ácidos graxos mono e poliinsaturados, ao contrário das gorduras de origem animal, que são ricas em ácidos graxos saturados. O óleo de soja é um dos óleos comestíveis mais susceptíveis à reação de oxidação devido ao seu maior grau de insaturação que se caracteriza pelo alto teor de ácido linoléico e pelo teor relativamente elevado de ácido linolênico (de 2 a $13 \%)^{[2]}$.

A principal causa da degradação de óleos e gorduras é conhecida como rancidez, a qual está associada à formação de produtos inaceitáveis organolepticamente devido a ocorrência de odores e sabores estranhos, além da perda de cor do produto, inativação de vitaminas e polimerização. A rancidez pode ser classificada como: 1) rancidez hidrolítica - ocorre na presença de umidade devido a ação de enzimas lípases que catalisam a reação de hidrólise, liberando ácidos graxos, e 2) rancidez oxidativa ou oxidação - ocorre devido a ação de enzimas lipoxigenases 
ou mediante ação não-enzimática, tais como a autoxidação e a fotoxidação.

A fotoxidação é um mecanismo que envolve a adição direta de oxigênio singlete $\left({ }^{1} \mathrm{O}_{2}\right)$ aos ácidos graxos insaturados. $\mathrm{O}$ oxigênio singlete reage diretamente com as duplas ligações presentes no óleo, produzindo hidroperóxidos conjugados e não conjugados. A forma mais importante de geração do oxigênio singlete é a exposição à luz na presença de um fotosensibilizador. Clorofilas e compostos heme contendo ferro são fotosensibilizadores que ocorrem naturalmente nos óleos vegetais. A estrutura básica destas moléculas é um anel porfirínico coordenado a um átomo central de magnésio (no caso da clorofila) e de ferro (no caso dos compostos heme). Estes compostos absorvem luz na região do UV próximo e do visível, transferindo a energia para o oxigênio triplete $\left({ }^{3} \mathrm{O}_{2}\right)$, tornando-o 1500 vezes mais reativo na forma de ${ }^{1} \mathrm{O}_{2}{ }^{[3]}$.

A energia radiante de fontes luminosas ou artificiais seja ultravioleta ou visível, afeta de modo significativo a estabilidade de alimentos fotosensíveis, pois tem efeito deteriorativo, uma vez que inicia e acelera reações de degradação através da ação fotoquímica. Embora a parte correspondente ao ultravioleta no espectro eletromagnético seja estreita (de 200 a $380 \mathrm{~nm}$ ), a luz emitida nesta região tem maior energia do que a luz emitida na região do visível (de 380 a 780nm), uma vez que a energia é diretamente proporcional à freqüência e inversamente proporcional ao comprimento de onda ${ }^{[4]}$.

Assim, quanto menor o comprimento de onda, maior a energia da radiação. Conseqüentemente, a radiação UV absorvida por grupos cromóforos presentes no produto induz a uma maior taxa de oxidação, pois tem maior energia do que a visível, sendo responsável pela maioria das degradações fotoquímicas. Por este motivo, compostos orgânicos denominados de estabilizadores de luz são usados em grande variedade de resinas plásticas a fim de prevenir a fotodegradação causada pela luz solar e por luz UV artificial.

Os estabilizadores de luz são classificados como aditivos de anti-envelhecimento e podem estabilizar a luz UV que incide na embalagem e nos produtos, evitando tais degradações. Esta estabilização é conseguida através de mecanismos diferentes, dependendo da natureza do aditivo.

Há três classes de estabilizadores de luz usados no material de embalagem, sendo que cada classe de estabilizador de luz age em uma etapa diferente da seqüência de reações de degradação fotoquímica:

1. Os absorvedores de $U V$, normalmente derivados de benzofenona ou benzotriazol, agem absorvendo a energia de radiação $U V$, de modo que previnem a formação de radicais livres e, portanto, atuam na fase inicial do processo degradativo. $\mathrm{O}$ consumo destes aditivos corresponde à cerca de $50 \%$ da demanda global de estabilizadores de luz, tomando por base dólares americanos;

2. Os bloqueadores de radicais livres, como é o caso do HALS (hindered amine light stabilizers), protegem os materiais poliméricos inibindo os radicais livres formados através de reações térmicas ou de oxidação. Estes compostos são amplamente utilizados em poliolefinas devido sua eficiência e desempenho;
3. Os supressores de estados excitados, representados por complexos de níquel, que atuam retirando a energia absorvida pelos cromóforos excitados do polímero e dissipando-a em forma de calor ou de radiação fluorescente ou fosforescente ${ }^{[5]}$.

A necessidade de proteção à luz UV não se restringe apenas aos polímeros, mas também aos produtos que são acondicionados em embalagens plásticas transparentes, uma vez que a maioria dos produtos industrializados que ficam dispostos em prateleiras de supermercados está exposta a algum tipo de luz e, conseqüentemente, está sujeita a fotoxidação.

Estudo realizado por Azeredo ${ }^{[6]}$, mostrou que a aplicação do absorvedor de UV 2-(2-Hidroxi-3,5-bis(1,1-dimetilbenzil)fenil)benzotriazol no material de embalagem possibilita a redução das taxas de fotoxidação do óleo de soja embalado em garrafas PET em cerca de $15 \%$.

No caso de sucos de frutas, a incidência de luz é uma das causas da oxidação de vitamina $\mathrm{C}$ e de carotenóides, pois acelera a reação do ácido ascórbico com grupos amino produzindo pigmentos escuros por polimerização, causando a perda de cor e alteração de outras propriedades organolépticas ${ }^{[7]}$.

De um modo geral, as reações de fotoxidação nos alimentos diminuem a vida útil do produto, causando mudanças sensoriais (alteração no odor/sabor), oxidação e desnaturação das proteínas. Assim, para proteger os produtos acondicionados da deterioração causada por reações de fotodegradação, são necessárias embalagens com barreira à luz uma vez que esta é catalisadora das reações de degradação.

No entanto, estudo preliminar realizado para avaliar a barreira à luz de embalagens plásticas transparentes utilizadas para o acondicionamento de produtos sensíveis à luz disponíveis no mercado brasileiro, tais como óleo comestível, suco de frutas, catchup, amendoim e maionese, mostrou que somente as embalagens de óleo utilizam aditivos absorvedores de luz ${ }^{[8]}$.

Os estudos disponíveis indicam a necessidade e a utilização de absorvedores de UV, porém não apresentam referências numéricas (p. e. concentração de aditivo versus barreira à luz UV conferida - eficácia do aditivo) que possam ser utilizadas como parâmetro de qualidade dos sistemas de embalagem. Assim, o objetivo deste trabalho foi avaliar o uso e a eficácia de absorvedores de UV como promotores de barreira à luz em embalagens de PET utilizadas para o acondicionamento de óleo comestível disponíveis no mercado brasileiro, visando disponibilizar informações para a especificação técnica e controle sanitário de embalagens para produtos alimentícios sensíveis à luz.

\section{Experimental}

\section{Materiais}

Foram avaliadas garrafas de PET de $900 \mathrm{~mL}$, com massa de 22 a $33 \mathrm{~g}$, espessura mínima da parede de 0,18 a $0,23 \mathrm{~mm}$, empregadas para o acondicionamento de óleos comestíveis disponíveis no mercado, adquiridas no varejo em Campinas (Figura 1). Foram analisadas embalagens de 12 marcas comerciais de óleo vegetal produzido por 6 fabricantes distintos, que representam cerca de $60 \%$ do mercado brasileiro. 


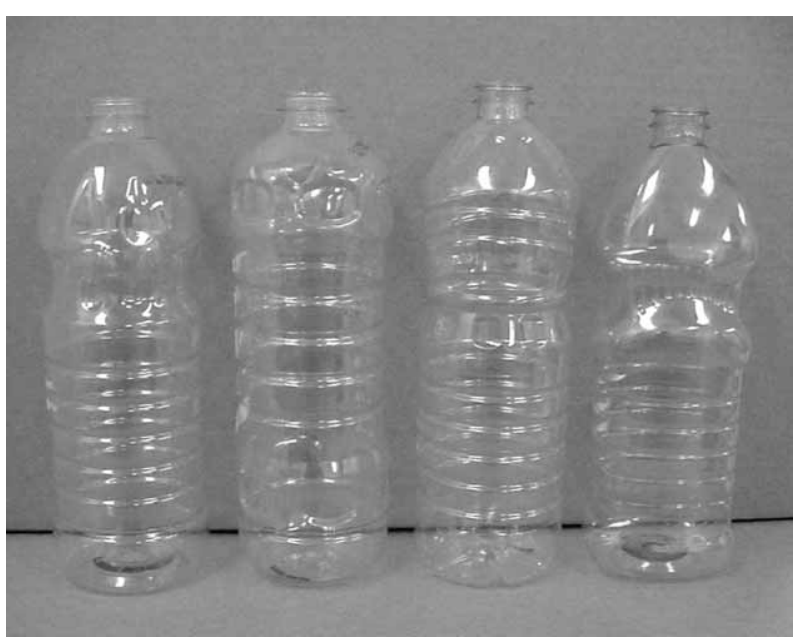

Figura 1. Exemplos de amostras de embalagem de PET para óleo comestível avaliadas neste estudo.

Tabela 1. Absorvedores de UV considerados neste estudo ${ }^{[9]}$.

\begin{tabular}{|c|c|c|c|}
\hline Código & Nome químico & $\begin{array}{l}\text { Número } \\
\text { CAS }\end{array}$ & $\begin{array}{l}\text { Marcas } \\
\text { comerciais }\end{array}$ \\
\hline \multirow{5}{*}{ UV-1 } & \multirow{5}{*}{$\begin{array}{l}\text { 2-(2-Hidroxi-3,5-bis(1,1- } \\
\text { dimetilbenzil)fenil)benzotriazol }\end{array}$} & \multirow{5}{*}{$2440-22-4$} & Tinuvin $\mathrm{P}$ \\
\hline & & & Mark LA 32 \\
\hline & & & Uvasorb SV \\
\hline & & & Lowilite 55 \\
\hline & & & Eversorb 71 \\
\hline \multirow{4}{*}{ UV-2 } & \multirow{4}{*}{$\begin{array}{l}\text { 2-(2'- Hidroxi-3'-terc-butil-5'- } \\
\text { metilfenil)-5-clorobenzotriazol }\end{array}$} & \multirow{4}{*}{$3896-11-5$} & Tinuvin 326 \\
\hline & & & Mark LA 36 \\
\hline & & & Lowilite 26 \\
\hline & & & Eversorb 73 \\
\hline \multirow{4}{*}{ UV-3 } & \multirow{4}{*}{$\begin{array}{l}\text { 2-(2'-Hidroxi-3',5'-di-terc- } \\
\text { butilfenil)-5-clorobenzotriazol }\end{array}$} & \multirow{4}{*}{$3864-99-1$} & Tinuvin 327 \\
\hline & & & Mark LA 34 \\
\hline & & & Lowilite 27 \\
\hline & & & Eversorb 73 \\
\hline \multirow{2}{*}{ UV-4 } & \multirow{2}{*}{$\begin{array}{c}\text { 2-(2-Hidroxi-3,5-bis }(1,1- \\
\text { dimetilbenzil)fenil)benzotriazol }\end{array}$} & \multirow{2}{*}{ 70321-86-7 } & Tinuvin 234 \\
\hline & & & Eversorb 76 \\
\hline
\end{tabular}

Os reagentes acetonitrila, grau HPLC (Merck, Alemanha), metanol, grau HPLC (Merck, Alemanha), diclorometano, grau p.a. (Merck, Alemanha) e água ultrapura (Milli-Q) foram usados sem purificação prévia.

Os absorvedores de UV Tinuvin $\mathrm{P}^{\circledR}$ Tinuvin $326^{\circledR}$, Tinuvin $327^{\circledR}$ e Tinuvin $234^{\circledR}$ (Tabela 1) foram fornecidos pela Ciba Specialty Chemicals Inc. (Basel, Suíça) foram usados como padrão. Os aditivos foram utilizados conforme recebidos.

\section{Métodos}

As embalagens foram condicionadas por pelo menos 40 horas à temperatura de $23 \pm 2{ }^{\circ} \mathrm{C}$ e os ensaios conduzidos nas mesmas condições de condicionamento ${ }^{[10]}$.
A caracterização das amostras foi feita empregando-se cinco garrafas para as amostras que apresentaram o absorvedor de U.V. em sua formulação e uma garrafa para as amostras em que não se detectou a presença do aditivo.

\section{Transmissão de luz}

A determinação da transmissão de luz das amostras baseouse em metodologia descrita por ALVES et al. ${ }^{[11]}$. A porcentagem da transmissão de luz especular (valor de transmitância obtido quando se mede apenas o fluxo de luz transmitido na mesma direção do feixe incidente, ou seja, com dispersão menor que um grau) das amostras foi determinada empregando-se um espectrofotômetro UV-Visível de marca Perkin Elmer, modelo Lambda 3B, na região do ultravioleta (comprimento de onda abaixo de $380 \mathrm{~nm}$ ) e do visível (comprimento de onda maior do que $380 \mathrm{~nm}$ ).

Os corpos-de-prova foram recortados do ombro, corpo e calcanhar das embalagens com dimensões de $10 \mathrm{~mm}$ de largura por $40 \mathrm{~mm}$ de comprimento. Estes se encontravam livres de sujeira, sem impressão e representativos da unidade amostrada. Os espectros foram obtidos para a faixa de comprimento de onda de 200 a $700 \mathrm{~nm}$, a uma velocidade de varredura de $120 \mathrm{~nm} / \mathrm{min}$.

\section{Quantificação de absorvedor de UV}

$\mathrm{O}$ tratamento empregado para a extração do aditivo das amostras baseou-se em metodologia descrita por Monteiro et al ${ }^{[12]}$. As diferentes regiões da embalagem foram cortadas em pedaços pequenos, colocadas em contato por 12 horas em diclorometano e submetidas à $1 \mathrm{~h}$ de extração em banho de ultra-som. Após a etapa de extração, foi feita uma filtração (papel Whatman $\mathrm{n}^{\circ} 1$ ) e o volume completado com diclorometano para $50 \mathrm{~mL}$. A seguir foi feita uma nova filtração, com filtro de $0,45 \mu \mathrm{m}$ e realizada a injeção do extrato em um cromatógrafo líquido de alto desempenho, HP 1100, com detector de conjunto de diodos UV-Visível, nas seguintes condições: coluna: fase reversa C 18, 250 x 4mm; temperatura: $40^{\circ} \mathrm{C}$; fase móvel: $100 \%$ acetonitrila; fluxo: $1,5 \mathrm{~mL} / \mathrm{min}$; comprimento de onda: $200 \mathrm{~nm}$; volume de injeção: $10 \mu \mathrm{L}$.

A quantificação de absorvedor de U.V. nas amostras de garrafa de PET foi realizada em quintuplicata, considerandose as embalagens nas quais identificou-se a presença de aditivo no ensaio de transmissão de luz.

\section{Resultados e Discussão}

\section{Avaliação da Barreira à Luz}

A transparência de um material é função de várias propriedades, tais como a transmissão de luz, a transmissão de luz especular (valor de transmitância obtido quando se mede apenas o fluxo de luz transmitido na mesma direção do feixe incidente, ou seja, com dispersão menor do que um grau) e o haze (valor de transmissão de luz obtido quando se mede apenas o feixe de luz transmitido, que sofre uma dispersão superior a $2,5^{\circ} \mathrm{em}$ relação à direção do feixe de luz incidente). Portanto, os resultados aqui apresentados com relação à barrei- 


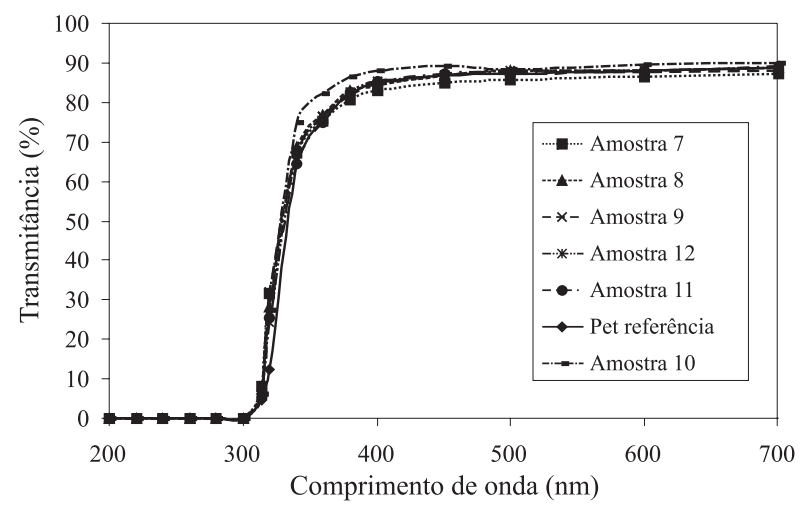

Figura 2. Espectros de transmissão de luz especular para as embalagens de óleo comestível avaliadas que não apresentaram barreira ao UV.
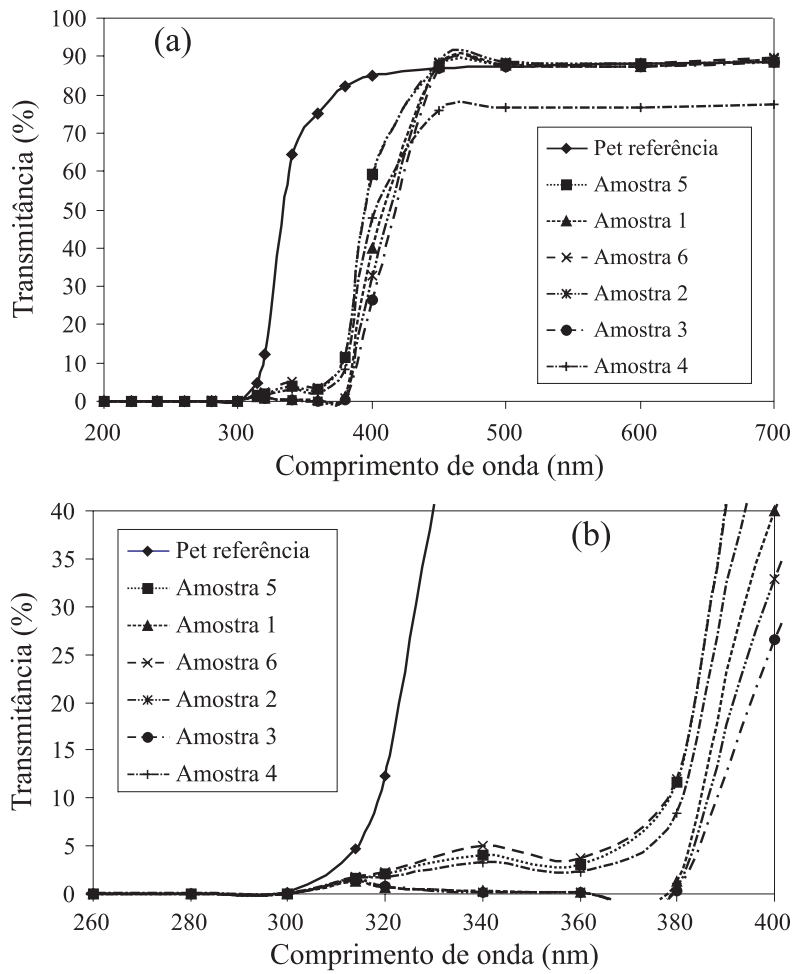

Figura 3. Espectros de transmissão de luz especular para embalagens de óleo comestível avaliadas que apresentaram barreira ao UV: (a) escala $100 \%$ e (b) escala ampliada.

ra à luz das embalagens de PET são indicativos desta barreira, porém não refletem completamente a realidade. Isto porque ainda existe uma fração da luz transmitida pela embalagem, que atinge o produto e pode acelerar sua degradação, mas que não está sendo monitorada por meio dos resultados de transmissão de luz especular ${ }^{[13]}$. De qualquer modo, os resultados são confiáveis uma vez que materiais com alta qualidade ótica, como o PET, apresentam "haze" muito reduzido.

Os espectros de transmissão de luz especular das diferentes marcas de produto foram comparados entre si e também com a porcentagem de transmitância de luz do PET referência (sem a adição de estabilizadores à luz). Assim, por meio da comparação dos espectros das amostras em relação a esse PET referência, pode-se concluir quanto à presença ou não de absorvedores de luz em cada embalagem avaliada.
A presença de barreira à luz por aditivação foi constatada apenas nas embalagens de seis marcas comerciais de óleo comestível. É característico do PET apresentar transmissão de luz nula para os comprimentos de onda inferiores a 300nm, conforme pode ser observado pelo espectro do PET sem adição de absorvedores de UV - PET referência (Figura 2). Assim, a confirmação da presença de absorvedores de UV deve-se à queda da porcentagem de transmitância de luz na faixa de comprimento de onda de 300 a 400nm, o que não ocorre no PET referência (Figuras 3).

Portanto, observou-se que apenas $50 \%$ das amostras de embalagem de óleo vegetal analisadas apresentaram barreira ao UV, sendo que as Amostras 1, 2 e 3 apresentaram a melhor barreira, enquanto as amostras 4,5 e 6 apresentaram barreira à luz semelhante (Figura 3b).

Não se observou relação alguma entre a barreira à luz e a espessura mínima média das garrafas de óleos analisadas. As espessuras apresentaram valores que não variam de acordo com a eficiência de proteção à luz, mas sim aleatoriamente, ou seja, as embalagens com maior barreira não possuiam valores de espessuras médias maiores.

Uma vez que não há diferença de espessura entre as amostras avaliadas, estes fatos podem ser decorrentes de: 1) emprego de aditivos distintos, ou 2) uso do mesmo aditivo, porém em concentrações diferentes. Essas observações foram avaliadas no ensaio de quantificação de absorvedor de U.V.

Os resultados mostraram que os óleos acondicionados nas embalagens das amostras 1 a 6 apresentam maior proteção contra a fotodegradação do produto, devido à barreira à luz de suas embalagens na região do comprimento de onda do UV. Estes resultados não são muito satisfatórios, pois as amostras cujas embalagens não apresentaram barreira à luz estão mais expostas à fotoxidação, que reduz a vida-de-prateleira do óleo devido às alterações sensoriais.

No entanto, os óleos acondicionados nestas embalagens não-aditivadas apresentaram impresso no rótulo o prazo de validade de 12 meses (valor igual àquele das embalagens com barreira à luz). O que provavelmente está incorreto, uma vez que de acordo com Arruda ${ }^{[14]}$, a vida útil do óleo de soja acondicionado em garrafas de PET de $900 \mathrm{~mL}$ e armazenado no escuro aumenta de 60 para 180 dias quando a concentração inicial de oxigênio no espaço livre da embalagem é reduzida de $>15 \%$ para $0-3 \%$, indicando que a oxidação do óleo de soja acondicionado em garrafas de PET pode ser minimizada por meio da inertização do produto com nitrogênio durante o processamento, o que reduz o oxigênio disponível no espaço livre da embalagem.

Estes resultados indicam que a qualidade dos óleos vegetais comercializados varia muito de produtor para produtor e/ou que os fabricantes de óleo comestível desconhecem ou questionam a necessidade de barreira à luz da embalagem para este tipo de produto. De qualquer modo a vida útil do produto depende da perda de qualidade definida pelo fabricante e pelo respectivo consumidor.

Segundo informação obtida junto aos produtores de óleo comestível / aditivos, a aditivação das embalagens aumenta o 
custo das mesmas, podendo representar cerca de $10 \%$ do custo. Como o óleo comestível é um produto de baixo valor agregado, somente a comprovação efetiva da necessidade de uso do aditivo na garrafa poderá motivar os produtores de óleo a fazer uso de absorvedores de UV em suas embalagens.

Os produtores de óleo têm investido em tecnologias de refino como tentativas para diminuir a taxa de oxidação, eliminando os agentes precursores ou catalisadores. Porém, o processo de refino não é uma garantia de que o óleo engarrafado em embalagem de PET transparente tenha uma vidade-prateleira de um ano. Desse modo, o uso de absorvedores de UV nas garrafas PET para óleo conferem uma proteção adicional ao produto.

A luz solar tem $6,1 \%$ de UV em sua composição espectral, isso a torna prejudicial e deve ser evitada através da aditivação das embalagens transparentes. Além disso, as lâmpadas usadas nos supermercados também apresentam efeito nocivo ao produto ${ }^{[15]}$. Os absorvedores de luz atuam como filtros, absorvendo comprimentos de onda abaixo de $400 \mathrm{~nm}$, podendo diminuir as taxas de fotoxidação do óleo de soja em cerca de $15 \%{ }^{[6]}$.

Com base nestes resultados pode-se questionar a nãoaditivação das garrafas de PET para óleo comestível disponíveis no mercado. No entanto, algumas indústrias já reconhecem a fragilidade do óleo comestível e a real necessidade do uso de estabilizadores à luz em embalagens transparentes.

\section{Quantificação de Absorvedor de U.V.}

Para a identificação do absorvedor de UV empregado nas amostras de mercado analisadas, duas características cromatográficas do aditivo foram consideradas: o tempo de retenção e o espectro de absorção no UV. Compararam-se os dados de cada amostra com o tempo de retenção e o espectro de absorção no UV de diversos padrões de absorvedores de UV (UV-1, UV-2, UV-3 e UV-4, Tabela 1), injetados sob as mesmas condições cromatográficas. O perfil dos cromatogramas obtidos pode ser observado na Figura 4.

Os resultados indicaram que, apesar de fabricadas por diferentes empresas, em todas as amostras de embalagem de PET para óleo comestível analisadas está sendo utilizado um mesmo absorvedor de UV da classe dos benzotriazóis, 2-(2'Hidroxi-3'-terc-butil-5'-metilfenil)-5-clorobenzotriazol (UV2, Tabela 1). Este aditivo é aprovado pela legislação brasileira para uso em embalagens plásticas para contato com alimentos ${ }^{[16]}$, porém seu limite de migração está sendo revisado ${ }^{[17]}$.

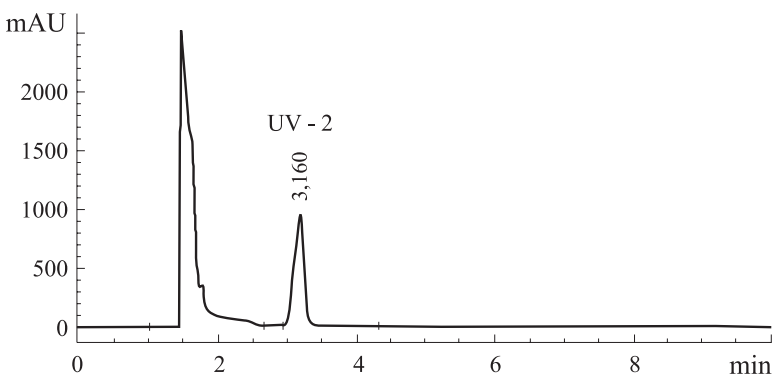

Figura 4. Cromatograma de absorvedor de UV detectado na Amostra 1.(UV2 , tempo de retençao $=3,16 \mathrm{~min}$ )
Tabela 2. Quantificação do aditivo UV-2 nas amostras de óleo comestível $(\mathrm{mg} / \mathrm{kg}){ }^{*}$

\begin{tabular}{cccc}
\hline Amostra & Média & $\begin{array}{c}\text { Intervalo de } \\
\text { Variação }\end{array}$ & CV (\%) \\
\hline 1 & 1962 & $1917-2048$ & 2,8 \\
2 & 1659 & $1373-1928$ & 13,8 \\
3 & 2003 & $1832-2103$ & 5,6 \\
4 & 788 & $730-890$ & 7,7 \\
5 & 785 & $744-828$ & 4,7 \\
6 & 793 & $720-841$ & 5,9 \\
\hline
\end{tabular}

* Valores referentes a 5 determinações,

$\mathrm{CV}=$ coeficiente de variação

Quanto ao teor de aditivo utilizado, como pode ser observado na Tabela 2, as amostras se dividiram em dois grupos: as amostras 1,2 e 3 apresentaram concentrações da ordem de $0,20 \%$ em massa, enquanto as amostras 4, 5 e 6 da ordem de $0,08 \%$ em massa. Em ambos os casos, o aditivo confere barreira à luz à embalagem, sendo esta superior para a concentração maior (Figura 3).

No entanto, concentrações superiores a $0,08 \%$ provavelmente apresentam pouco acréscimo à estabilidade do produto de acordo com estudo realizado por Coltro et al. ${ }^{[17]}$ no qual foi avaliada a eficiência quanto à barreira à luz de um tipo de absorvedor de UV (UV-2) em embalagem de PET confeccionada com diferentes concentrações do aditivo. Segundo os autores, concentrações de absorvedor de UV superiores a $0,112 \%$ apresentaram um incremento pequeno na barreira a luz, além de ter sido verificado que mesmo a menor concentração de aditivo utilizada $(0,08 \%)$ provavelmente era suficiente para conferir barreira à luz necessária para o aumento da vida-útil do produto (óleo comestível) armazenado a $25^{\circ} \mathrm{C}$. Entretanto, a confirmação desta hipótese depende da realização de um estudo de vida-de-prateleira.

\section{Conclusões}

Os resultados obtidos mostraram que:

- Das embalagens de PET para óleo comestível disponíveis no mercado avaliadas neste estudo somente seis marcas comerciais ( $50 \%$ das marcas avaliadas) apresentaram barreira ao U.V.;

- Todas as embalagens aditivadas apresentaram o aditivo UV-2, independentemente do fabricante do produto e/ou da embalagem;

- O mercado está empregando duas concentrações distintas do aditivo: $0,08 \%$ e $0,20 \%$.

Apesar do prazo de validade impresso nos rótulos das embalagens ser o mesmo para todas as marcas de óleo comestível avaliadas (um ano), provavelmente os produtos acondicionados em embalagens de PET com barreira ao U.V. têm uma vida-útil superior às demais.

Portanto, ainda se faz necessário um esclarecimento maior dos fabricantes de óleo, a respeito da necessidade de uso de absorvedor de U.V. em garrafas de PET para óleo, além de orientação para o uso da concentração de aditivo mais ade- 
quada nas embalagens, uma vez que isto se reflete no custo do produto.

Assim, a continuidade deste trabalho é a avaliação da vidade-prateleira de óleos comestíveis acondicionados em embalagens de PET, a fim de fornecer subsídios técnicos para os prazos de validade apresentados nestas embalagens.

\section{Agradecimentos}

As autoras agradecem a FAPESP pelo apoio financeiro e pela bolsa concedida à Ana Elisa Penteado Buratin.

\section{Referências Bibliográficas}

1. Datamark - Produtos - Óleo Comestível (on line). Atualizado em Janeiro de 2004. Disponível em http:// www.datamark.com.br; data de acesso 13/02/2004.

2. Quinteiro, L. M. C; Vianni, R. - Ciência Tecn. Alim., 15, p. 29 (1995).

3. Labuza, T. F. - Critical Review Foods Tech., 2 (3), p. 355 (1971).

4. Silverstein, R. M.; Bassler, G. C.; Norril, T. - "Identificação Espectrométrica de Compostos Orgânicos". Alencastro, R.B., Faria, R.B. (trad.), $3^{\mathrm{a}}$ ed. Rio de Janeiro: Guanabara, p. 203 (1987).

5. Machado, M. C. M. S. T. - "Absorvedores de Radiação Ultravioleta em Embalagens Plásticas em Óleos Vegetais: Metodologia Analítica e Estudo de Migração". Tese de Doutorado, Universidade Estadual de Campinas, Brasil (1997).

6. Azeredo, H. M. C. - "Maximização da estabilidade oxidativa de óleo de soja acondicionado em garrafas plásticas". Tese de Doutorado, Universidade Estadual de Campinas, Brasil (2001).

7. Alves, R. M. V.; Garcia, E. E. C. - Coletânea ITAL, 23 (2), p. 105 (1993).

8. Coltro, L., Buratin, A. E. P. - “Avaliação da Barreira à Luz de Embalagens Plásticas para Alimentos e Bebidas do Mercado Brasileiro", in: Anais do XV Congresso Brasileiro de Engenharia e Ciência dos Materiais, cód. 401-013, Natal - RN, nov (2002).

9. Gugumus, F. - "Light Stabilizers", in: Plastics Additives Handbook, cap. 2. Zweifel, H. (ed.), Hanser Publishers, Munich (2001).

10. ASTM. D618-00 - "Standard practice for conditioning plastics for testing". ASTM Standard on Disc. Philadelphia, v. 08.01 (2001).

11. Alves, R. M. V., Oliveira, L. M., Coltro, L., Garcia, E. E. C., Sarantópoulos, C. I. G. L. \& Padula, M. - "Ensaios para Avaliação de Embalagens Plásticas Rígidas", CETEA/ITAL, Campinas (1998).

12 Monteiro, M., Nerín, C., Rubio, C., Reyes, F. G. R. - J. High Res. Chromatogr. 21, p. 317 (1998).

13. Sarantópoulos, C. I. G. L., Oliveira, L. M., Padula, M., Coltro, L., Alves, R. M. V., Garcia, E. E. C. "Embalagens Plásticas Flexíveis: Principais Polímeros e Avaliação de Propriedades", CETEA/ITAL, Campinas (2002).

14. Arruda, C. S. - "Efeito da Concentração de oxigênio na estabilidade oxidativa do óleo de soja em garrafas PET (Polietileno Tereftalato)". Dissertação de Mestrado, Universidade Federal de Mato Grosso do Sul, Brasil (2003).

15. Pascall, M. A.; Harte, B. R.; Giacin, J. R.; Gray, J. I. - J. Food Sci.. 60 (5), p. 1116 (1995).

16. Agência Nacional De Vigilância Sanitária - ANVISA "Disposições gerais para embalagens e equipamentos plásticos em contato com alimentos e seus anexos". Resolução n. 105, de 19 de maio de 1999. Diário Oficial (da República Federal do Brasil), Brasília, p.21-34, 20 de maio de 1999. Sec.I.

17. Coltro, L., Padula, M., Saron, E. S., Borguetti, J., Buratin, A. E. P. - Pack. Techn. Sci., 16, p. 15 (2003).

Enviado: 02/03/04

Reenviado: 20/05/04 Aprovado: 31/05/04 